\title{
Evaluation of a non-mydriatic camera in Indian and European diabetic patients
}

\author{
R MOHAN,' E M KOHNER,' S J ALDINGTON,' I NIJHAR,' V MOHAN,' \\ AND H M MATHER ${ }^{2}$ \\ From the 'Diabetic Retinopathy Unit, Hammersmith Hospital, Ducane Road, London W12 0HS, and ${ }^{2}$ Ealing \\ Hospital, Uxbridge Road, Southall, Middlesex UB1 3HW
}

SUmmary The value of the Canon CR3-45NM non-mydriatic fundus camera in screening for diabetic retinopathy has been assessed in two ethnic groups, namely, 45 Indian and 40 European diabetic patients. There was $72 \%$ agreement between ophthalmoscopy by an ophthalmologist and the photographic assessment, and $100 \%$ agreement on clinically important lesions requiring treatment. However, peripheral retinal lesions, seen on ophthalmoscopy but lying outside the photographic field, occurred in $4 \%$ of eyes. $6 \%$ of photographs were totally unassessable and an additional $12 \%$ were only partially assessable. The prevalence and severity of retinopathy was similar in Indian and European patients. The advantages and disadvantages of the non-mydriatic camera in screening for diabetic retinopathy are discussed.

Ophthalmoscopy and conventional retinal photography are the two methods most often used to diagnose diabetic retinopathy. Both require pupillary dilatation, which may be a disadvantage in epidemiological studies and in busy clinic settings, when many patients need to be screened relatively quickly. The recently introduced non-mydriatic fundus camera ${ }^{12}$ seems to be the ideal tool for these situations, but its evaluation is incomplete. The present study was undertaken to assess the value of the Canon CR3-45NM camera in screening for retinopathy in a busy diabetic clinic. We particularly wished to see whether the camera was suited for use in Indian 'Asian' patients who have dark irises, which may dilate less readily, and have pigmented fundi, which might be more difficult to evaluate.

\section{Material and methods}

PATIENTS

Forty-five Indian patients (33 male, 12 female) and 40 European patients (23 male, 17 female) were studied. They were consecutive patients attending the Ealing Hospital diabetic clinic who met the entry criteria, which were an age at diagnosis greater than 20 years, a known duration of diabetes of at least four years, and no history of ketosis. Fifteen Indian and 24

Correspondence to Dr E M Kohner.
European patients were receiving insulin treatment. Other clinical features are shown in Table 1.

\section{METHODS}

Visual acuities were assessed in a darkened room at 6 $m$ by means of a standard Snellen chart with internal illumination. The best visual acuity obtained with the patient's own glasses and/or pinhole was recorded. The patient was then seated in a dark room for not less than five minutes, until adequate dilatation of the pupils, checked with the camera, had been achieved. Photography was performed with the Canon CR3$45 \mathrm{NM}$ non-mydriatic wide-angle $\left(45^{\circ}\right)$ camera, used in a totally darkened room. The camera uses an infrared illumination source instead of the common white light. The fundus is viewed prior to flash

Table 1 Clinical features of Indian and European patients

\begin{tabular}{llll}
\hline & $\begin{array}{l}\text { Indians } \\
(45)\end{array}$ & $\begin{array}{l}\text { Europeans } \\
(40)\end{array}$ & \\
\hline Mean age (years) & $54 \cdot 9$ & $62 \cdot 1$ & $<0 \cdot 01$ \\
$\begin{array}{l}\text { Median known duration (years) } \\
\text { Mean fasting blood glucose }\end{array}$ & 8 & 12 & NS \\
$\quad(m m o l / 1)$ & $10 \cdot 8$ & $12 \cdot 1$ & NS \\
$\begin{array}{l}\text { Mean body mass index* } \\
\text { Hypertension } \dagger\end{array}$ & $26 \cdot 2$ & $25 \cdot 8$ & NS \\
& 10 & 13 & NS \\
\hline
\end{tabular}

*Body mass index $=$ weight $(\mathrm{kg}) /$ height $(\mathrm{m})^{2}$.

†Hypertension diagnosed by WHO criteria. 
exposure by means of an infrared-sensitive video camera built into the fundus camera, and is displayed to the operator on a small TV monitor. No direct view through the fundus camera optics is therefore required. Automatic interlocks disable the infrared video camera when the flash exposure is made. One Polaroid photograph was taken of the right eye, centred on the fovea and including areas lateral to the macula and nasal to the disc, and both superior and inferior temporal arcades. After 2 to 5 minutes (to allow the pupils to dilate after the first flash) the left eye was also photographed. The use of Polaroid pictures enabled rephotography if their quality was inadequate. A record was made of the patient's reaction to the flash.

One drop each of phenylephrine $10 \%$ and tropicamide $1 \%$ was then instilled into both eyes. When the pupil was fully dilated, direct ophthalmoscopy was performed by an ophthalmologist (RM) without knowledge of the photographic findings. Details of the fundus examination were systematically recorded. Any retinopathy was assessed for severity of haemorrhages plus microaneurysms, hard exudates, cotton-wool spots, venous abnormalities, intraretinal microvascular abnormalities (IRMA), new vessels (both on the disc and elsewhere), and fibrous tissue (on the disc and elsewhere). Each type of lesion was judged against transparencies from the Early Treatment of Diabetic Retinopathy Study standard photographic slides, ${ }^{3}$ which were placed on an adjacent radiographic viewing box, to facilitate comparison. For the purpose of this report retinopathy was considered to be minimal if only one to five microaneurysms and not more than one haemorrhage were present; mild if there were other lesions such as haemorrhages and hard exudates, but not requiring photocoagulation; maculopathy if there were haemorrhages and exudates in the perifoveal area and marked discolouration of the fovea; and proliferative if there were new vessels on the disc, and/or in the retinal periphery, and photocoagulated if there were scars of photocoagulation or the patient gave a history of laser treatment.

The photographs were coded and assessed in a 'blind' manner by EMK for the presence and severity of retinopathy and for photographic quality. This was undertaken twice, in random order, and at least two weeks apart. Assessment of retinopathy was also by comparison with the ETDRS standard slides. Oedema formation or retinal elevation could not be graded because stereo photographs were not available. Photographic quality was assessed on an arbitrary scale from 1 to 5,1 being excellent, 2 good and easily assessable, 3 assessable with some difficulty, 4 only part of the field assessable, and 5 unassessable.
Table 2 Visual acuity in Indian and European eyes

\begin{tabular}{lcc}
\hline & Indian & European \\
\hline $6 / 6$ & 44 & 32 \\
$6 / 9$ & 18 & 20 \\
$6 / 12$ & 1 & 4 \\
$6 / 18$ & 9 & 8 \\
$6 / 24$ & 0 & 3 \\
$6 / 36$ & 2 & 4 \\
$6 / 60$ & 0 & 1 \\
Worse than $6 / 60$ & 12 & 6 \\
\hline
\end{tabular}

The study was approved by the Ealing Hospital Ethical Committee. Student's $t$ test and $\chi^{2}$ tests were used for statistical comparisons.

\section{Results}

\section{VISUAL ACUITY}

Visual acuities of 43 Indian patients were obtained. Only one patient was blind in both eyes, and most had good vision (Table 2 ). There were only 12 eyes with a visual acuity less than $6 / 36$, and only five patients with vision worse than 6/9 in both eyes.

Visual acuities of 39 European patients were obtained. No patient was blind in both eyes, but two patients had only $6 / 36$ vision in their better eye. Impaired visual acuity occurred with similar frequency in the two ethnic groups.

\section{OPHTHALMOSCOPIC FINDINGS}

The ophthalmoscopic assessments are detailed in Table 3 and summarised in Table 6 . In Indian patients retinopathy was present in 41 eyes and absent in 40 eyes; nine fundi (in seven patients) could not be adequately assessed because of cataract formation. In European patients retinopathy was present in 45 eyes, absent in 31 eyes, and four fundi (in three patients) could not be adequately assessed. There was no significant difference in the presence of severity of retinopathy between the two ethnic

Table 3 Assessment of retinopathy by ophthalmologist

\begin{tabular}{lll}
\hline & Indian eyes & European eyes \\
\hline No retinopathy & 40 & 31 \\
Minimal & 10 & 14 \\
Mild & 16 & 13 \\
Maculopathy & 8 & 5 \\
Maculopathy (in spite of PC*) & - & 5 \\
New vessels (no PC) & - & 1 \\
New vessels (in spite of PC) & 3 & 2 \\
PC now mild retinopathy & 2 & 1 \\
Outside standard fields $\dagger$ & 2 & 4 \\
Not assessable & 9 & 4 \\
\hline
\end{tabular}

*PC=photocoagulation.

†Retinopathy outside $45^{\circ}$ photographic field only. 
Table 4 Photographic quality

\begin{tabular}{llllll}
\hline Grade* & \multicolumn{2}{l}{ Indians } & & \multicolumn{2}{l}{ Europeans } \\
\cline { 2 - 3 } \cline { 5 - 6 } & lst & 2nd & & lst & 2nd \\
& reading & & & reading & \\
& 29 & 31 & 25 & 28 \\
& 24 & 26 & 24 & 23 \\
1 & 18 & 13 & 15 & 13 \\
2 & 9 & 10 & 11 & 10 \\
3 & 6 & 6 & 4 & 5 \\
4 & & &
\end{tabular}

*See text for definitions of photographic quality grading system.

groups. Most patients with retinopathy had minimal or mild lesions only. New vessels were present in five eyes despite previous photocoagulation, and also in one eye which had not been treated. Five eyes had persistent extensive hard exudates despite previous treatment.

\section{PHOTOGRAPHIC QUALITY}

Photographs were taken of 165 out of 170 eyes (86 Indian and 79 European). Their quality was assessed as either excellent or good (grades 1 or 2) in 105 $(64 \%)$ (the mean of two readings). However, $6 \%$ of photographs were totally unassessable (grade 5) and a further $12 \%$ were only partially assessable (grade $4)$. The poor quality photographs were evenly distributed between the two ethnic groups (Table 4) and throughout the three months of the study.

\section{WITHIN OBSERVER VARIATION}

There was agreement between first and second readings on the presence or absence of retinopathy in 158 of 165 eyes, a $96 \%$ reproducibility (Table 5). The seven photographs producing different readings were of patients (four Indians and three Europeans) adjudged to have minimal retinopathy on one reading and none on the other. There was also excellent agreement between the first and second assessments

Table 5 Photographic assessment

\begin{tabular}{|c|c|c|c|c|}
\hline \multirow{2}{*}{$\begin{array}{l}\text { Retinopathy } \\
\text { grading }\end{array}$} & \multicolumn{2}{|l|}{ Indians } & \multicolumn{2}{|c|}{ Europeans } \\
\hline & $\begin{array}{l}\text { lst } \\
\text { reading }\end{array}$ & 2nd & $\begin{array}{l}\text { lst } \\
\text { reading }\end{array}$ & 2nd \\
\hline None & 26 & 30 & 29 & 26 \\
\hline Minimal & 17 & 13 & 16 & 19 \\
\hline Mild & 17 & 17 & 16 & 16 \\
\hline Maculopathy & 7 & 7 & 8 & 8 \\
\hline NVD/NVE* & 0 & 0 & 1 & 1 \\
\hline $\mathrm{PC} \dagger+\mathrm{NVD} / \mathrm{NVE}$ & 4 & 4 & 0 & 0 \\
\hline $\mathrm{PC}+$ mild or minimal & 3 & 3 & 2 & 2 \\
\hline Unassessable & 11 & 11 & 7 & 7 \\
\hline
\end{tabular}

*NVD/NVE $=$ new vessels on the disc, and new vessels elsewhere. $\dagger \mathrm{PC}=$ photoagulation.
Table 6 Comparison of photographic and ophthalmological assessment of retinopathy

\begin{tabular}{llrrll}
\hline & & \multicolumn{3}{c}{ Ophthalmological assessment } \\
\cline { 3 - 6 } & & \multicolumn{5}{c}{ Present } & Absent & Unassessable & Total \\
\hline Europeans & & & & 0 & 43 \\
Photographic & Present & 34 & 9 & 0 & 29 \\
assessment & Absent & 8 & 21 & 0 & 7 \\
& Unassessable & 3 & 1 & 3 & 79 \\
& Totals & 45 & 31 & 3 & \\
Indians & & & & & 51 \\
Photographic & Present & 35 & 15 & 1 & 9 \\
assessment & Absent & 3 & 22 & 1 & 26 \\
& Unassessable & 3 & 2 & 4 & 96 \\
& Totals & 41 & 39 & 6 & \\
\hline
\end{tabular}

Among the European patients there were 34 eyes which had retinopathy on both ophthalmological and photographic assessment. In nine eyes the ophthalmologist found no lesions, while there were some found on the photographs. There were eight occasions when retinopathy was found on examination by the ophthalmologist but not on photography.

In 21 eyes neither the ophthalmologist nor the photographic grader found lesions. There were three photographs judged unassessable when the ophthalmologist found lesions and one where the photograph was unassessable when no lesions were found by the ophthalmologist. Finally there were three eyes that could not be assessed by the ophthalmologist, and their photographs were also unassessable.

The findings of the Indian patients' eyes can be interpreted in a similar fashion.

of the severity of retinopathy. The concurrence between first and second readings was similarly good in Indian and European eyes.

\section{COMPARISON OF OPHTHALMOLOGICAL AND PHOTOGRAPHIC GRADING}

There was concurrence between the ophthalmological and photographic assessments of the presence or absence of retinopathy (and its assessability) in 61 $(71 \%)$ of 86 Indian eyes and $58(73 \%)$ of 79 European eyes (Table 6). There was no disagreement between the two assessment methods on clinically significant macular lesions, new vessels, or previous photocoagulation. The overall concurrence was 119 of 165 , or $72 \%$. There were 21 disagreements in European eyes, of which eight were reported to have retinopathy by the ophthalmologist alone. In four of these cases the lesions were outside the photographic field, and the other four had minimal lesions only. Of the nine European eyes reported to have retinopathy by the photographic reader alone three were considered to have mild and six minimal retinopathy. The 25 disagreements on Indian eyes included 15 adjudged to have minimal or mild retinopathy on photographic assessment alone. In one of the three Indian eyes reported to have retinopathy by ophthalmoscopy alone the lesions lay outside the photographic field. 
DISCOMFORT OF PHOTOGRAPHS

Thirteen Indian and two European patients experienced some discomfort during the photographs, and four Indians thought it sufficient to decline yearly examination. Two of these photographs were partially or totally unassessible (grade 4 or 5), but in the other two their quality was good. Only one of the four had cataracts.

\section{Discussion}

The early recognition of diabetic retinopathy is vitally important because it is now a treatable condition. However, there is no consensus on which method of screening (whether ophthalmoscopy by physicians, ophthalmologists, or opticians, or by use of the non-mydriatic fundus camera) is most suitable for general use. This study highlights some advantages and disadvantages of the camera. It is broadly comparable to ophthalmoscopy through dilated fundi by an ophthalmologist in detecting retinopathy, in determining its severity, and in enabling patients to be selected for further investigation and consideration of laser treatment. It is almost certainly superior to ophthalmoscopy by physicians working in busy diabetic clinics, ${ }^{4}$ especially if performed through undilated pupils. However, consultant ophthalmologists would not undertake routine screening of all diabetic patients because of the time involved, though clinical assistants could perhaps be trained for this task.

Unfortunately there are also some significant drawbacks. Firstly, a proportion of photographs are technically unsatisfactory. In this study $6 \%$ were unassessable and an additional $12 \%$ only of limited use. These figures are broadly similar to those of previous studies. ${ }^{12}$ Difficulties in obtaining satisfactory photographs are more likely to occur in patients who have cataracts or are elderly. Many such patients may not attend a hospital clinic, and an adequate photographic assessment would therefore be vital in community use. Furthermore, if a poor picture were obtained, it would be difficult for a photographic technician to decide the cause, the urgency of referral, and whether the patient should be referred to a diabetic clinic or to an eye clinic for consideration of cataract extraction.

Secondly, the camera will fail to detect lesions which lie outside the photographic field. In our study this occurred in two of 86 Indian eyes and in four of 79 European eyes. Klein et al. have suggested that retinopathy may lie outside the photographic field in $8-15 \%$ of cases. ${ }^{5}$ Thirdly, neither direct ophthalmoscopy nor a single retinal photograph are adequate to screen for macular oedema. This is a significant defect of both screening methods because of the findings of the Early Treatment of Diabetic Retinopathy Study that early macular oedema with normal or near normal vision benefits most markedly from treatment. ${ }^{6}$ Many patients would require referral for either stereo photography or fluorescein angiography to ensure that they are treated at an early stage when vision can be maintained. Fourthly, some patients found the photography uncomfortable, and four said that they would not consent to further photographs.

This study provides some evidence that both the prevalence and severity of retinopathy are similar in comparable groups of Indian and European diabetics. This is consistent with ophthalmoscopic findings in large unselected groups of clinic patients. ${ }^{7}$ The prevalence of known diabetes in Indians is strikingly high, with a 5 to 7 fold increase compared with Europeans in age group 40-64 years. ${ }^{8}$ Thus the numbers of Indians developing diabetic retinopathy which requires treatment may increase rapidly over the next few years. The fundus camera was equally suitable for use with both patient groups, though more Indians experienced discomfort with the flash. This concurs with the findings of Klein et al., who found that patients with brown irises were more discomforted by the flash than patients with blue irises. $^{5}$

The discrepancies between the ophthalmoscopic and photographic assessments are rather difficult to explain in view of a recent paper ${ }^{2}$ which reported a virtually complete concordance between the two methods. However, the disagreements in the current study were on mild or minimal retinopathy, and many were probably due to over-reading of the photographs when in doubt, to ensure earlier reexamination of the eyes. There were no disagreements in deciding which patients required referral for further invetigation and possible treatment.

In conclusion, this study suggests that Indian diabetic patients are equally prone to developing retinopathy as comparable European patients. The Canon CR3-45NM non-mydriatic fundus camera has been validated as a reliable way of screening for retinopathy, but it has several limitations which need to be borne in mind if it is used as the only method of assessment within the community.

The camera was donated by the British Diabetic Association VM received a Wellcome research grant. We thank Miss Joan Welch for secretarial help.

\section{References}

1 Ryder REJ, Vora JP, Atiea JA, Owens DR, Hayes TM, Young S. Possible new method to improve detection of diabetic retinopathy: Polaroid non-mydriatic retinal photography. $\mathrm{Br} \mathrm{Med} J$ 1985; 291 : 1256-7.

2 Williams R, Nussey S, Humphry R, Thompson G. Assessment of non-mydriatic photography in detection of diabetic retinopathy. Br Med J 1986; 293: 1140-2. 
3 Early Treatment Diabetic Retinopathy Study Research Group. Early treatment diabetic retinopathy study: manual of operations. Department of Epidemiology and Preventative Medicine, Division of Clinical Investigation, University of Maryland School of Medicine. Baltimore, 1980: chapter 13.

4 Sussman EJ, Tsiaras WG, Soper KA. Diagnosis of diabetic eye disease. JAMA 1982; 247: 3231-4.

5 Klein R, Klein BEK, Neider MW, Hubbard LD, Meuer SM, Brothers RJ. Diabetic retinopathy as detected using ophthalmoscopy, a nonmydriatic camera and a standard fundus camera. Ophthalmology 1985; 92: 485-91.
6 Early Treatment Diabetic Retinopathy Study Research Group. Photocoagulation of diabetic macular edema: early treatment diabetic retinopathy study report number 1 . Arch Ophthalmol 1985; 103: 1796-806.

7 Nicholl CG, Levy JC, Mohan V, Rao PV, Mather HM. Asian diabetes in Britain: a clinical profile. Diabetic Med 1986; 3: 25760 .

8 Mather HM, Keen H. The Southall diabetes survey: prevalence of known diabetes in Asians and Europeans. Br Med J 1985; 291: $1081-4$.

Accepted for publication 20 August 1987. 